\title{
Hochuekkito, a Kampo (traditional Japanese herbal) Medicine, Enhances Mucosal IgA Antibody Response in Mice Immunized with Antigen-entrapped Biodegradable Microparticles
}

\author{
Tsukasa Matsumoto $^{1,2}$, Masaaki Noguchi ${ }^{1}$, Osamu Hayashi ${ }^{3}$, Kimiko Makino ${ }^{4}$ and \\ Haruki Yamada ${ }^{1,2}$
}

${ }^{1}$ Kitasato Institute for Life Sciences \& Graduate School of Infection Control Sciences, Kitasato University, Tokyo 108-8641, ${ }^{2}$ Oriental Medicine Research Center, The Kitasato Institute, Tokyo 108-8642, ${ }^{3}$ Department of Health and Nutrition, Kagawa Nutrition University, Saitama 350-0288 and ${ }^{4}$ Faculty of Pharmaceutical Sciences, Tokyo

University of Science, Chiba 278-8510, Japan

\begin{abstract}
The effect of oral administration of Hochuekkito (HET; Bu-Zhong-Yi-Qi-Tang in Chinese), a traditional Japanese herbal medicine, on mucosal IgA immune response was investigated. To induce the antigen-specific antibodies in mucosal site, ovalbumin (OVA)-entrapped biodegradable microparticles (OVA-microparticles) were used as an antigen. Mice were orally immunized with OVA-microparticles for 3 successive days with intragastric gavage. From 7 days after the onset of immunization, the mice were boosted twice a week with the same antigen for 2 weeks. HET or water alone was orally administered to the mice via the intragastric route from 7 days before to 27 days after the onset of immunization. Although no significant change in total secretory IgA antibody level was observed in intestinal and nasal washes, OVA-specific IgA titers in intestinal washes were significantly enhanced by oral administration of HET. When lymphocytes from spleen, peripheral blood and Payer's patches were investigated for cytokines production, it was found that the IFN- $\gamma$ secretion from the lymphocytes was increased by the administration of HET. Microarray analysis of Peyer's patch cells revealed enhanced expression of L-selectin gene. The increase of L-selectin positive cells in B lymphocytes fraction was observed in Peyer's patch cells and peripheral blood mononuclear cells by flow cytometry. These results suggest that the enhanced IFN- $\gamma$ secretion and increased population of L-selectin positive B lymphocytes by orally administered HET may partly contribute to enhancement of $\operatorname{IgA}$ immune response against intestinal antigens, and orally administered HET may strengthen defensive systems against various pathogens and food antigens in intestine.
\end{abstract}

Keywords: DNA microarray-Hochuekkito-Kampo-L-selectin-mucosal IgA-Peyer's patch-OVA-microparticle

\section{Introduction}

Hochuekkito (HET; Bu-Zhong-Yi-Qi-Tang in Chinese) is one of Kampo (Japanese herbal) medicines, which consists of 10 component herbs, and well-known

For reprints and all correspondence: Haruki Yamada, Kitasato Institute for Life Sciences, Kitasato University, Tokyo 108-8641, Japan.

E-mail: yamada@lisci.kitasato-u.ac.jp
Kampo formulas used as tonic. This formula has been identified as an effective drug to improve function of the digestive system and to strengthen defensive system against various infections. It promotes certain biological activities including enhancement of natural killer cells (1) and macrophage activity (2). HET also has an inhibitory effect on influenza virus infection via enhancement of host immune responses in virus-infected mice (3). 
Recently, we have found that orally administered HET enhanced immune response against the intranasally administered antigen (4).

The gut-associated lymphoreticular tissues exist on intestinal mucosal sites and play an important role in host defense including $\operatorname{IgA}$ response in the mucosal immune system (5). The central aspect of a mucosal immune response is the generation of antigen-specific $\operatorname{IgA}$ antibodies at the external secretions. Once produced by mature plasma cells, IgA is transported onto the mucosal surface, where it interacts with invading pathogens by inhibiting their adherence and forming immune complexes (6).

The inner surface of the intestinal tract possesses a large area of mucosal membranes, and the intestinal epithelial cells (IEC) sit at the interface between a lumen and a lymphocyte-rich lamina propria. The cross talk that occurs between these compartments serves to maintain intestinal homeostasis. Because Kampo medicines are taken orally, the gastric mucosal immune system may act as one of the major targets for expression of pharmacological activity. However, the modulating activity of Kampo medicines on mucosal immune system is not fully understood.

In this research, we attempt to evaluate whether HET can stimulate $\operatorname{IgA}$ antibody response against intestinal antigen by using ovalbumin (OVA)-entrapped biodegradable microparticles (OVA-microparticles), and found that HET enhanced antigen-specific mucosal IgA response. The present article deals with the effect of orally administered HET on the enhanced mucosal IgA response against intestinal antigen.

\section{Materials and Methods}

\section{Materials}

Spray-dried extract preparation of HET (TJ-41, Lot No. 920041001PO) was kindly supplied by Tsumura \& Co. (Tokyo, Japan). HET for 1 day dose was prepared as follows: a mixture of Astragali Radix (4 $\mathrm{g}$, roots of Astragalus membranaceus Bunge), Atractylodis lanceae Rhizoma (4g, rhizomes of Atractylodes lancea DC.), Ginseng Radix (4 g, roots of Panax ginseng C.A. Meyer), Angelicae Radix (3g, roots of Angelica acutiloba Kitagawa), Bupleuri Radix (2g, roots of Bupleurum falcatum L.), Zizyphi Fructus (2 g, fruits of Zizyphus jujuba Miller var. inermis Rehder), Aurantii Bobilis Pericarpium (2g, pericarps of ripe fruits of Citrus unshu Markovich), Glycyrrhizae Radix (1.5 g, roots of Glycyrrhiza uralensis Fisch et DC.), Cimicifugae Rhizoma ( $1 \mathrm{~g}$, rhizomes of Cimicifuga simplex Wormskjord) and Zingiberis Rhizoma $(0.5 \mathrm{~g}$, rhizomes of Zingiber officinale Roscoe) was added to water and extracted at $100^{\circ} \mathrm{C}$ for $1 \mathrm{~h}$. The extracted solution was filtered and spray-dried to obtain dry extract powder $(5 \mathrm{~g})$. Ministry of Health, Labour and Welfare in Japan chose $5 \mathrm{~g}$ of the extract as a dosage for 1 day for adult human. Chemical profile of HET obtained by the 3D HPLC analysis is shown in Fig. 1.

\section{Mice}

Specific pathogen free $\mathrm{C} 3 \mathrm{H} / \mathrm{HeJ}$ female mice (6- to 8-weeks old) were obtained from SLC (Shizuoka, Japan). Mice were maintained in a $24 \mathrm{~h}$ light and dark cycle (12h of light, $12 \mathrm{~h}$ of darkness) and controlled temperature $\left(23 \pm 1^{\circ} \mathrm{C}\right)$ and they had free access to standard laboratory chow (Oriental Yeast Co., Tokyo, Japan) and water. The procedure from the Prime Minister's Office of Japan (No. 6 of March 27, 1980) for the care and use of laboratory animals was followed. The experiments were conducted in accordance with Guidelines for Animal Use and Experimentation of the Kitasato Institute (Tokyo, Japan), and the approval number of the animal experimentation was 2006-1-35-1 (Kitasato Institute). For oral administration to mice, HET extract was suspended in distilled water at a concentration of $100 \mathrm{mg} \mathrm{ml}^{-1}$. HET was orally administered through a gastric tube once a day (4:00 PM) in a volume of $100 \mu 1$ per $10 \mathrm{~g}$ of body weight, while control group was administered equal volumes of water alone. During the experiments, behavioral changes and/or motor deficit were not observed in between the control and HET administered groups, and decrease in body weight was also not observed (data not shown).

\section{Preparation of OVA-Microparticles}

The OVA-microparticles were prepared using the water-inoil-in-water emulsion solvent evaporation technique according to the methods of Jeffery et al. (7). OVA (albumin, chicken egg white, grade V, Sigma, St Louis, MO, USA) was dissolved in water to a concentration of 10\%. Poly(DL-lactide-co-glycolide, 50:50) (PLG; Sigma) was dissolved in dichloromethane to a concentration of $12 \%$. Polyvinyl alcohol (PVA, Sigma) was dissolved in water to a concentration of $2 \%$. One milliliter of aqueous OVA solution was emulsified with $10 \mathrm{ml}$ of PLG solution using an ultrasonic homogenizer (Type 200, Branson, Danbury, CT, USA). The resulting w/o emulsion was then emulsified at high speed with $100 \mathrm{ml}$ of aqueous PVA solution to produce a $\mathrm{w} / \mathrm{o} / \mathrm{w}$ emulsion. The $\mathrm{w} / \mathrm{o} / \mathrm{w}$ emulsion was then stirred magnetically for $18 \mathrm{~h}$ at room temperature and pressure, to allow solvent evaporation and microparticle formation. The microparticles were isolated by centrifugation, washed three times with water and freezedried. The surface of OVA-microparticles as observed under scanning electron microscope was free from any pores or cracks (Fig. 2). Protein content of 


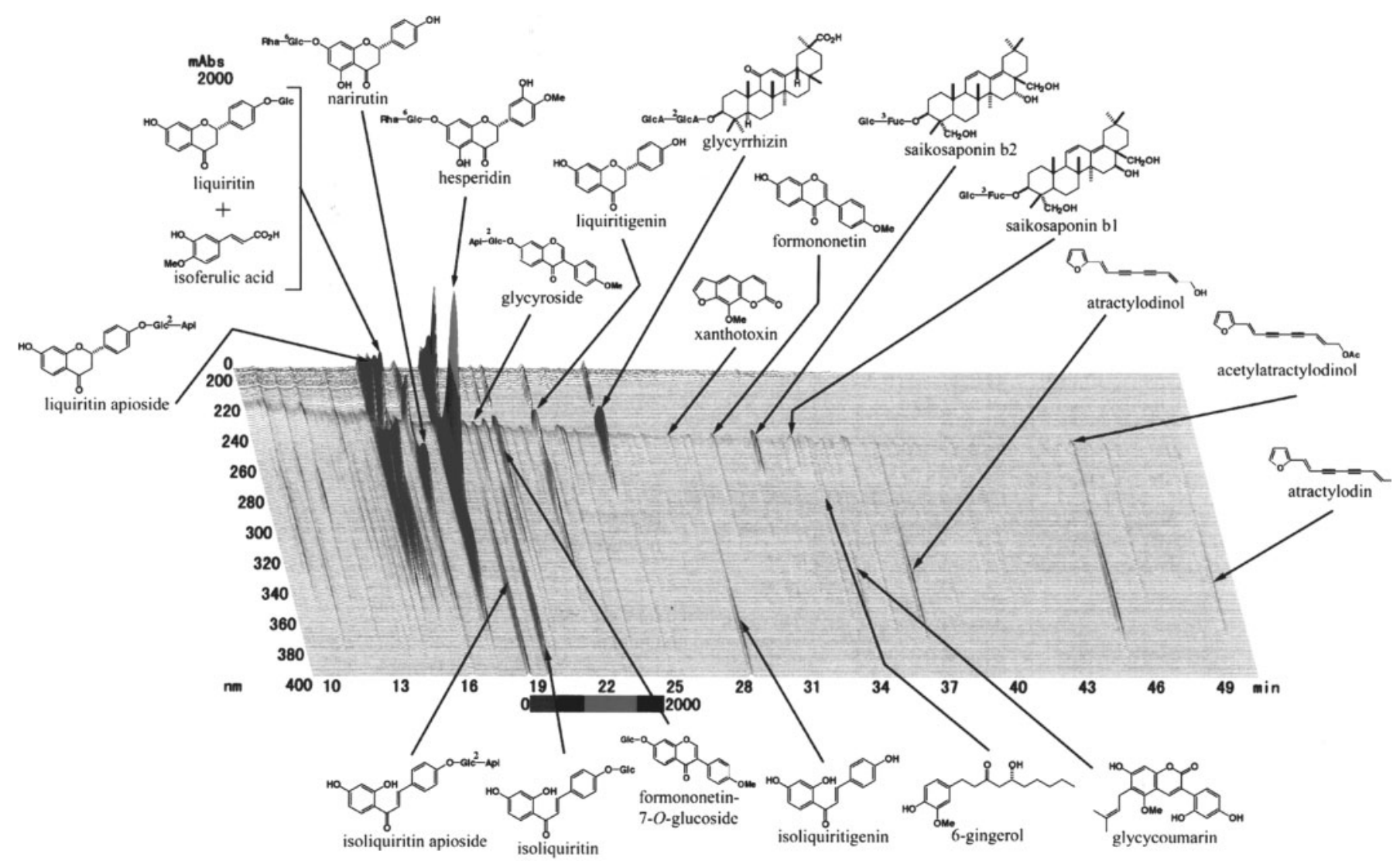

Figure 1. Chemical profile of HET analyzed by 3D HPLC. The each peak of HET in the HPLC profile was identified by comparison of the retention times and UV spectra of chemically defined standard compounds. HPLC condition was as follows: Column; Tosoh TSK GEL ODS-80Ts $(4.6 \times 250 \mathrm{~mm})$. Carrier A: $0.05 \mathrm{M}$ ammonium acetate $(\mathrm{pH}$ 3.6). Carrier B: Acetonitrile. Gradient: $10-100 \%$ carrier B linear in 60 min. Flow rate:

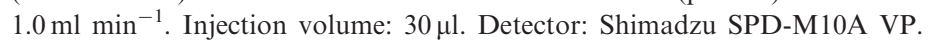

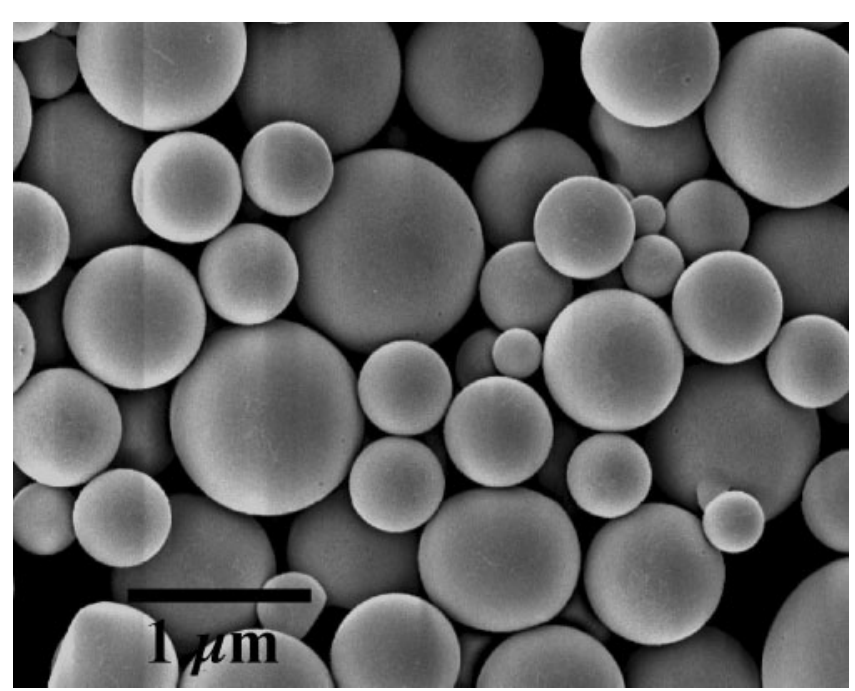

Figure 2. Scanning electron micrograph of OVA-microparticles. The dried preparation was covered with a $10 \mathrm{~nm}$ thick gold film by sputter coating (JEOL, JFC-1200 FINE COATER, Tokyo, Japan), then examined with a JSM-5600 scanning electron microscope (JEOL) operated at an acceleration voltage of $5 \mathrm{kV}$.
OVA-microparticles was measured using a bicinchoninic acid (8), and was $10.8 \%$ as OVA. OVA free blank microparticles were prepared identically in the absence of OVA.

\section{Schedule for Immunization of OVA and HET Administration}

OVA-microparticles were suspended in $0.5 \mathrm{ml}$ of water, and mice were immunized orally on days $0,1,2,7,10,14$ and 17 with $2 \mathrm{mg}$ of OVA antigen via the intragastric route. HET were orally administered to the mice with intragastric gavage from 7 days before to 27 days after the starting of immunization.

\section{Preparation of Nasal and Intestinal Washes}

The small intestine was dissected and placed on an icecold glass plate, and the lumen was flushed with $3 \mathrm{ml}$ of cold phosphate-buffered saline (PBS) containing $0.1 \%$ bovine serum albumin (BSA), $0.05 \%$ Tween 20 and a protease inhibitor mixture $\left(2.5 \mu \mathrm{g} \mathrm{ml}^{-1}\right.$ aprotinin, $2.5 \mu \mathrm{g} \mathrm{ml}^{-1}$ pepstatin and $2.5 \mu \mathrm{g} \mathrm{ml}^{-1}$ leupeptin) to collect the intestinal wash. The head of the mouse was removed and the lower jaw was excised, a hypodermic needle was 
inserted into the posterior opening of the nasopharynx, and $500 \mu \mathrm{l}$ of the flushing solution described earlier was injected to collect the nasal wash. The washes were centrifuged $10 \mathrm{~min}$ at $2330 \times \mathrm{g}$ and the supernatants were immediately frozen and stored at $-20^{\circ} \mathrm{C}$.

\section{Detection of Anti-OVA IgA Antibody and Total IgA by ELISA}

The specific anti-OVA IgA antibody content of the intestinal and nasal washes was determined by enzyme-linked immunosorbent assay (ELISA). The ELISA was performed as follows: microtiter plates (Immulon ${ }^{\circledR} 4 \mathrm{HBX}$, Thermo Labsystems; Franklin, MA, USA) were coated overnight with $100 \mu 1$ per well of $1 \%$ OVA. Unbound OVA on the plate was removed by washing with PBS containing $0.05 \%$ Tween 20 (PBST, $300 \mu 1)$ four times. The plate was further incubated with $1 \%$ BSA in PBS (PBS-BSA) $\left(300 \mu 1\right.$ per well) at $37^{\circ} \mathrm{C}$ for $1 \mathrm{~h}$, and washed with PBST four times. Serial dilution of the intestinal and nasal washes was done with PBS-BSA. The resulting dilutions were added to the wells $(100 \mu$ per well), and incubated at $37^{\circ} \mathrm{C}$ for $1 \mathrm{~h}$. After the plate was washed with PBST five times, biotin-labeled anti-mouse IgA (clone R5-140) (PharMingen, San Diego, CA, USA), which was diluted with PBST, was added to the wells and incubated at $37^{\circ} \mathrm{C}$ for $1 \mathrm{~h}$. Then the plate was washed six times with PBST. Streptavidin-alkaline phosphatase (Life Technologies, Gaithersburg, MD, USA) diluted with PBST $(1: 2000)$ was added to each well and the plates were then incubated at room temperature for 30 min. The plate was washed with PBST five times, and each well was incubated with $150 \mu$ l of chromogenic substrate solution ( $1 \mathrm{mg}$ of $p$-nitrophenylphosphate disodium salt in $1 \mathrm{ml}$ of $10 \%$ diethanolamine buffer, $\mathrm{pH} 9.8$ ) at room temperature. The absorbance at $405 \mathrm{~nm}$ was measured during incubation using a microplate reader (Model 450, Bio-Rad). Total IgA was measured by a standard sandwich ELISA using anti-mouse $\operatorname{IgA}$ (clone C10-3) and biotin-labeled anti-mouse IgA (R5-140) (PharMingen, San Diego, CA, USA).

\section{Detection of Cytokines by ELISA}

The interferon (IFN)- $\gamma$ and interleukin (IL)-4 were measured by using sandwich ELISA kit (Amersham Biosciences AB, Uppsala, Sweden). The tests were performed according to the supplier's instruction manuals.

\section{Preparation of Cell Suspension}

Under light ether anesthesia, blood was obtained aseptically by cardiac puncture, and spleen and Peyer's patches were removed. Peripheral blood mononuclear cells (PBMC) were prepared from heparinized whole blood using a standard Percoll density gradient. In brief, the blood was layered onto the top of the discontinuous gradient containing 67.5 and $40 \%$ of Percoll (Amersham Biosciences $\mathrm{AB})$. After centrifugation $(600 \times \mathrm{g}$ for $20 \mathrm{~min})$, the interface layer between 67.5 and $40 \%$ was carefully removed and washed twice with Hanks' balanced salt solution (HBSS), and then resuspended in RPMI 1640 containing $5 \%$ fetal bovine serum (FBS) at a final concentration of $2.5 \times 10^{6}$ cells $\mathrm{ml}^{-1}$. Splenocytes and Peyer's patch cells were isolated as previously described (9). The cell viability was uniformly $>95 \%$ as determined by trypan blue exclusion, and always $>95 \%$ of the cells showed lymphocyte and $<1 \%$ macrophage morphology with characteristic staining.

\section{Cell Culture and Cytokine Production Measurements}

The lymphocytes were suspended at a density of $2.5 \times 10^{6}$ cells $\mathrm{ml}^{-1}$ in RPMI $1640-5 \%$ FBS. Five hundred microliter of aliquots of cell suspension were dispensed into 48-well flat bottom microculture plates (Falcon 3048, Becton Dickinson, Franklin Lakes, NJ, USA) and cultured for $48 \mathrm{~h}$ at $37^{\circ} \mathrm{C}$ in a humidified atmosphere of $5 \% \mathrm{CO}_{2}-95 \%$ air with $1 \mu \mathrm{g} \mathrm{ml}^{-1}$ of anti-mouse CD3 (145-2C11) for the induction of cytokines. After the culture of lymphocytes, the culture supernatants were collected and stored at $-20^{\circ} \mathrm{C}$ for the quantitative analysis of cytokines.

\section{Isolation of Total RNA and Generation of Biotin-labeled cRNA}

Total RNA was purified using an RNeasy Mini kit (Qiagen, Valencia, CA, USA). Residual genomic DNA in the total RNA samples was removed by incubation with 10 units DNase I per $100 \mu \mathrm{g}$ total RNA (Ambion, Austin, TX, USA) at $37^{\circ} \mathrm{C}$ for $30 \mathrm{~min}$. RNA integrity was verified using the Bioanalyzer 1000 (Agilent Technologies, Palo Alto, CA, USA). Biotin-labeled cRNA was generated in a two-step procedure. Initially, first-strand cDNAs were synthesized from $4.0 \mu \mathrm{g}$ of total RNA using 1.0 unit of SuperScript II RT (Invitrogen, Carlsbad, CA, USA) in the presence of $100 \mathrm{p}$ mole T7 promoter Oligo dT primer. After second-strand synthesis, the DNA was purified with a DNA Clean and Concentrator-5 kit (Zymo Research, Orange, CA, USA). The purified doublestranded cDNA was transcribed into cRNA using the MEGAscript in vitro transcription kit (Ambion). The in vitro transcription reaction was carried out in a total volume of $23.0 \mu \mathrm{l}$ consisting of $3.0 \mu \mathrm{l}$ of double-stranded cDNA, $2.3 \mu \mathrm{l}$ of $10 \times$ Ambion reaction buffer, $2.3 \mu \mathrm{l}$ of $10 \times$ Ambion T7 enzyme mix and $15.4 \mu \mathrm{l}$ of NTP labeling mix $(7.5 \mathrm{mM}$ ATP, $7.5 \mathrm{mM}$ GTP, $5.625 \mathrm{mM}$ UTP, $5.625 \mathrm{mM}$ CTP, $1.875 \mathrm{mM}$ biotin-16-UTP and $1.875 \mathrm{mM}$ biotin-11-CTP). The in vitro transcription reaction was incubated at $37^{\circ} \mathrm{C}$ for $16 \mathrm{~h}$ in a thermocycler. The cRNA was purified with an RNeasy Mini kit (Qiagen). 


\section{Microarray Analysis}

A total of 500 unique murine sequences were used to construct high-density oligonucleotide DNA microarrays. Oligonucleotides were synthesized in situ using photo deprotection chemistry with the Maskless Array Synthesizer system (NimbleGen, Madison, WI, USA). The microarrays were pre-hybridized with $1 \times$ MES hybridization buffer $(100 \mathrm{mM}$ 2-morpholinoethanesulfonic acid, $1.0 \mathrm{M} \mathrm{Na}^{+}, 20 \mathrm{mM}$ EDTA, $0.01 \%$ Tween 20 ), $40 \mu \mathrm{g}$ of herring sperm DNA and $200 \mu \mathrm{g}$ of acetylated BSA at $45^{\circ} \mathrm{C}$ for $15 \mathrm{~min}$ followed by hybridization with $10 \mu \mathrm{g}$ of denatured and fragmented cRNA per microarray at $45^{\circ} \mathrm{C}$ for $20 \mathrm{~h}$ with constant rotation. After hybridization, the microarrays were immediately washed extensively with non-stringent buffer (6× SSPE, $0.01 \%$ Tween 20) at room temperature followed by a stringent wash $(100 \mathrm{mM}$ MES salt and free acid solution, $0.1 \mathrm{M} \mathrm{Na}^{+}, 0.01 \%$ Tween 20) at $45^{\circ} \mathrm{C}$. After the final rinse with the nonstringent buffer, the microarrays were stained with $1 \times$ stain buffer $\left(100 \mathrm{mM}\right.$ MES, $1 \mathrm{M} \mathrm{Na}^{+}, 0.05 \%$ Tween 20, $50 \mathrm{mg} \mathrm{ml}^{-1}$ BSA and $1 \mathrm{mg} \mathrm{ml}^{-1}$ Cy3-streptavidin) at room temperature for $25 \mathrm{~min}$. The stain buffer was removed, and the microarrays were rinsed once more with non-stringent buffer. The microarrays were immediately dried under a stream of argon gas and scanned using an Axon GenePix 4000B scanner (Molecular Devices, Union City, CA, USA) at $5 \mu \mathrm{m}$ resolution. The data were extracted from the raw images using NimbleScan software (NimbleGen, Madison, WI, USA), and then processed using NANDEMO Analysis software (GeneFrontier, Tokyo, Japan). Genes were regarded as changed if the expression differed over 1.5-fold between the two groups.

\section{Flow Cytometry}

The surface phenotypes of cells were identified by using monoclonal antibodies. FITC-labeled anti-CD3 (clone 145-2C11), PE-labeled anti-CD45R/B220 (RA3-6B2) and PE-labeled anti-CD62L (MEL-14) were purchased from PharMingen (San Diego, CA, USA). Fluorescence staining was performed at $4^{\circ} \mathrm{C}$ in $200 \mu 1$ HBSS-FBS, after treatment of cells with unlabeled anti-CD16/32 Ab $(2.4 \mathrm{G} 2)$ in the same amount of staining buffer. Stained cells were then fixed with $1 \%$ paraformaldehyde dissolved in PBS and analyzed by flow cytometry (FCM) on EPICS ELITE with logarithmic amplifier (Coulter Corp., Hialeah, FL, USA). Lymphoid cells were gated by the forward and side scatter gating method for the analysis of the lymphocyte population.

\section{Statistical Analysis}

Data were expressed as mean $\pm \mathrm{SD}$ and differences between groups were analyzed by analysis of variance
(ANOVA) followed by post hoc analysis using Scheffe's test using a personal computer with the StatView-J program for Macintosh (SAS Institute Inc., Cary, NC, USA), and Welch's and Student's $t$-test were performed with DA Stats (ver 1.0, freeware soft, copyright ${ }^{\circledR} 1993$ by Dr O. Nagata) after the variances of data were examined using the $F$-test. The $P$-values $<0.05$ were considered significant.

\section{Results}

\section{Stimulation of Intestinal IgA Immune Response Against Intestinal Antigen}

Mice were orally immunized with OVA-microparticles 3 successive days with intragastric gavage. From 7 days after the onset of immunization, mice were boosted twice a week with the same antigen for 2 weeks. HET was orally administered to them via the intragastric route from 7 days before to 27 days after the onset of immunization. The intestinal washes were collected at day 27 from mice for measurement of titers of OVAspecific IgA antibody. By oral immunization of OVA-microparticle, OVA-specific IgA antibody was successfully induced in intestine (Fig. 3A). When HET was orally administered to the mice with the immunization, OVA-specific IgA antibody titers in intestinal washes were more significantly enhanced than that in water-administered control (Fig. 3A). In order to know whether HET enhances a basal level of secretory IgA production in the mucosal site, total IgA titer in intestinal washes were measured. No significant change in total IgA antibody level was observed by administration of HET in intestinal washes (Fig. 3B).

\section{Enhancement of IgA Immune Response in the Distant Mucosal Tissue Against Intestinal Antigen}

To evaluate whether HET can stimulate IgA antibody response in distant mucosal tissues, the OVA-specific $\operatorname{IgA}$ antibody titers in nasal washes were measured. No significant rise in OVA-specific $\operatorname{IgA}$ antibody titer in nasal washes was observed by oral immunization of OVA-microparticle alone (Fig. 3C). However, the IgA antibody titers in nasal washes were markedly enhanced by administration of HET, and the antibody titer was significantly higher than that of nasal washes from un-immunized mice (Fig. 3C). No significant change in total IgA antibody level was observed by the administration of HET in nasal washes (Fig. 3D). These results demonstrate the ability of orally administered HET to act as a mucosal adjuvant for the induction of specific $\operatorname{IgA}$ antibody responses in distant mucosal tissues. 



Figure 3. Effect of oral administrations of HET on OVA-specific IgA titer and total $\operatorname{IgA}$ antibody content in intestinal and nasal washes. OVA was entrapped into microparticles and then administered orally for immunization. Mice were immunized orally on days $0,1,2,7,10,14$ and 17 with $2 \mathrm{mg}$ of OVA antigen via the intragastric route. HET $\left(1000 \mathrm{~m} \mathrm{~kg}^{-1}\right)$ were orally administered to the mice with intragastric gavage from 7 days before to 27 days after the start of immunization. The intestinal and nasal washes were collected at day 28 , and then the anti-OVA IgA antibody and total IgA content of the intestinal and nasal washes were determined by ELISA. (A) Anti-OVA IgA titer of intestinal wash. (B) Total IgA content of intestinal wash. (C) Anti-OVA IgA titer of nasal wash. (D) Total IgA content of nasal wash. Note: in our preliminary experiment, the administration of OVA free blank microparticles did not induce IgA immune response in gastric mucosa (data not shown). Data were expressed as mean \pm SD $(n=10)$, and differences between groups were analyzed by ANOVA followed by post hoc analysis using Scheffe's test.

\section{Enhancement of IFN- $\gamma$ Secretion from Lymphocytes}

To clarify the mechanisms of enhancement of mucosal IgA antibody response by HET, we studied the effect of HET on modulation of Th1-Th2 balance. When HET $\left(1000 \mathrm{mg} \mathrm{kg}^{-1}\right)$ was administered orally for 1 week, the IFN- $\gamma$ secretions of lymphocytes from spleen, peripheral blood and Peyer's patches were significantly higher than that of the cells from the control mice (Fig. 4A-C). Whereas, the IL-4 secretions of lymphocytes from spleen, peripheral blood and Peyer's patches were not changed by oral administration of HET (Fig. 4D-F). These results suggest that HET may promote differentiation of the lymphocytes toward the Th1 type cell.

\section{Microarray Analysis of Gene Expression in Peyer's Patch Cells}

Peyer's patch is the important lymphoid tissues in the intestine, and are known as the inductive sites for $\operatorname{IgA}$
A

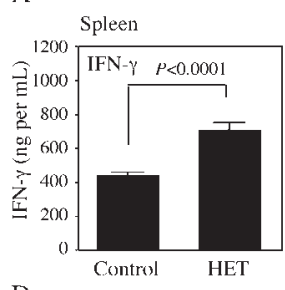

B

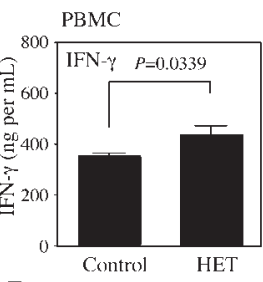

C Peyer's patches

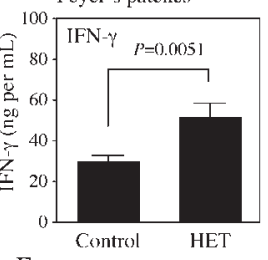

D Spleen

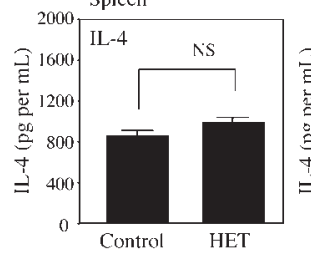

E PBMC

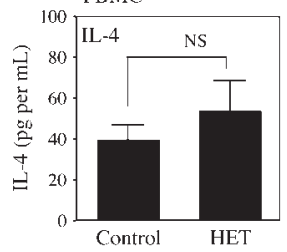

F Peyer's patches

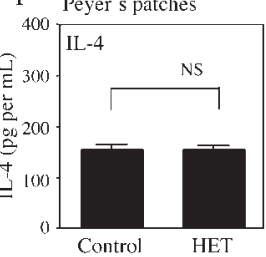

Figure 4. Secretion of IFN- $\gamma$ and IL-4 by lymphocytes from the mice orally administered HET. HET $\left(1000 \mathrm{mg} \mathrm{kg}^{-1}\right)$ was orally administered for 1 week, and then the lymphocytes were isolated from spleen, peripheral blood and Payer's patches, respectively. The lymphocytes $\left(2.5 \times 10^{6}\right.$ cells ml$\left.^{-1}\right)$ were cultured for $48 \mathrm{~h}$ under the stimulation with anti-CD3 antibody $\left(1 \mu \mathrm{g} \mathrm{ml}^{-1}\right)$. After the culture of lymphocytes, the culture supernatants were collected and the concentrations of IFN- $\gamma$ and IL-4 were analyzed by ELISA. Data were expressed as mean \pm SD $(n=10)$, and differences between groups were analyzed by Welch's and Student's $t$-test.

production (10). To study the mechanisms of enhancement of mucosal IgA antibody response by HET, the changes in gene expression of Peyer's patch cells by administration of HET were investigated using DNA microarray. HET was administered for 1 week, and then Peyer's patch cells were isolated and gene expression was analyzed by microarray. When expression of 500 genes in Payer's patch cells were analyzed, eight genes showed significantly different expression in HET administered mice compared with control (Table 1). Of the eight genes, analysis focused on the up-regulation of L-selectin (also known as CD62L) gene expression, because L-selectin was widely considered most important for homing of lymphocytes (11-13).

\section{Increase of the L-selectin Positive Cells in B Lymphocytes}

In order to confirm the up-regulation of L-selectin by orally administered HET, the immunophenotypes of Peyer's patch cells and PBMC were investigated using FCM. While the percentage of $\mathrm{CD}^{-} \mathrm{CD}^{-} 2 \mathrm{~L}^{-}$cells did not change, the percentage of $\mathrm{CD}^{-} \mathrm{CD}^{-} 2 \mathrm{~L}^{+}$cells was increased significantly in Peyer's patch cells from HETtreated mice compared with vehicle control mice (Table 2). The proportion of $\mathrm{CD}^{-} \mathrm{CD}_{2} \mathrm{~L}^{+}$cells to $\mathrm{CD}^{-}$cells was increased significantly in both Peyer's patch cells and PBMC from HET-treated mice compared with vehicle control mice (Table 2). It is widely known that $\mathrm{CD} 3$ is one of surface marker of $\mathrm{T}$ lymphocytes. Because both Peyer's patch cells and PBMC were mainly composed of $\mathrm{T}$ and $\mathrm{B}$ lymphocytes (data not shown), the $\mathrm{CD}^{-}$cells were presumed to be $\mathrm{B}$ lymphocytes, though 
Table 1. Effect of HET on gene expression in Peyer's patch cells

\begin{tabular}{lllll}
\hline Accession No & Gene annotation & Expression & Fold change & $P$-value \\
\hline NM_009692 & Apolipoprotein A-I (Apoa1) & Up & 1.7 & $4.0 \times 10^{-4}$ \\
Z16410 & B-cell translocation gene 1 & Up & 2.3 & $2.1 \times 10^{-5}$ \\
NM_008008 & Fibroblast growth factor 7 & Down & 2.7 & $2.3 \times 10^{-2}$ \\
X58712 & Mitogen-activated protein kinase (p42) & Up & 2.0 & $5.4 \times 10^{-4}$ \\
NM_008562 & Myeloid cell leukemia sequence 1 (Mcl1) & Up & 2.0 & $1.3 \times 10^{-4}$ \\
NM_011346 & Selectin, lymphocyte (L-selectin, CD62L) & Up & 2.0 & $5.6 \times 10^{-3}$ \\
NM_011529 & TRAF family member-associated NF-kappa B (Tank) & Up & 1.9 & $4.5 \times 10^{-3}$ \\
X99582 & Leukocyte-derived seven transmembrane domain receptor & Up & 1.9 \\
\hline
\end{tabular}

Oligonucleotides for microarray were synthesized in situ using photo deprotection chemistry with the Maskless Array Synthesizer system. HET was administered for 1 week, and then Peyer's patch cells were isolated and the gene expression was analyzed by the microarray. The data were extracted from the raw images using NimbleScan software and then processed using NANDEMO Analysis software. Genes were regarded as changed if the expression differed over 1.5 -fold between the cells of HET and that of control.

Table 2. Effect of orally administered HET on phenotype of lymphocytes from Peyer's patches and peripheral blood.

\begin{tabular}{rrr}
\hline Control & HET & $P$-value \\
\hline
\end{tabular}

Percent of phenotype in total cells

Payer's patch cells

$\begin{array}{rrr}\mathrm{CD}^{+} & 27.01 \pm 3.15 & 24.65 \pm 2.92 \\ \mathrm{~B} 220^{+} & 68.94 \pm 3.39 & 71.63 \pm 2.92 \\ \mathrm{CD}^{+}{ }^{\mathrm{CD} 62 L^{+}} & 8.34 \pm 1.34 & 7.06 \pm 1.65 \\ \mathrm{CD}^{+}{ }^{+} \mathrm{CD}_{2} \mathrm{~L}^{-} & 18.24 \pm 2.15 & 17.50 \pm 1.30 \\ \mathrm{CD}^{-}{ }^{-} \mathrm{CD}_{2} \mathrm{~L}^{+} & 39.94 \pm 3.79 & 43.44 \pm 2.76 \\ \mathrm{CD}^{-}{ }^{-} \mathrm{CD}_{2} \mathrm{~L}^{-} & 33.51 \pm 2.49 & 31.99 \pm 2.68\end{array}$

PBMC

$\begin{array}{rrr}\mathrm{CD}^{+} & 78.69 \pm 2.01 & 80.11 \pm 2.38 \\ \mathrm{~B} 220^{+} & 13.21 \pm 1.41 & 12.62 \pm 2.01 \\ \mathrm{CD}^{+}{ }^{+} \mathrm{CD} 62 \mathrm{~L}^{+} & 71.75 \pm 2.67 & 72.32 \pm 2.18 \\ \mathrm{CD}^{+}{ }^{+} \mathrm{CD}_{2} \mathrm{~L}^{-} & 5.63 \pm 0.63 & 5.41 \pm 0.58 \\ \mathrm{CD}^{-}{ }^{-} \mathrm{CD}_{2} \mathrm{~L}^{+} & 15.44 \pm 1.95 & 15.74 \pm 1.70 \\ \mathrm{CD}^{-}{ }^{-} \mathrm{CD}_{2} \mathrm{~L}^{-} & 7.16 \pm 1.14 & 6.56 \pm 0.95\end{array}$

Ratio of phenotype

Payer's patch cells

$$
\begin{array}{rrrr}
\mathrm{CD}^{+} / \mathrm{B} 220^{+} & 0.39 \pm 0.06 & 0.35 \pm 0.05 & \\
\mathrm{CD}^{+}{ }^{+} \mathrm{CD} 62 L^{+} / \mathrm{CD}^{+} & 0.69 \pm 0.04 & 0.72 \pm 0.04 & \\
\mathrm{CD}^{-}{ }^{-} \mathrm{CD}_{2} \mathrm{~L}^{+} / \mathrm{CD} 3^{-} & 0.54 \pm 0.04 & 0.58 \pm 0.03 & 0.021
\end{array}
$$

PBMC

\begin{tabular}{rlll}
$\mathrm{CD}^{+} / \mathrm{B}^{2} 20^{+}$ & $6.02 \pm 0.72$ & $6.53 \pm 1.28$ & \\
$\mathrm{CD}^{+} \mathrm{CD}^{2} \mathrm{~L}^{+} / \mathrm{CD}^{+}$ & $0.93 \pm 0.01$ & $0.93 \pm 0.01$ & \\
$\mathrm{CD}^{-}{ }^{-} \mathrm{CD} 62 \mathrm{~L}^{+} / \mathrm{CD}^{-}$ & $0.68 \pm 0.03$ & $0.71 \pm 0.03$ & 0.038 \\
\hline
\end{tabular}

HET $\left(1000 \mathrm{mg} \mathrm{kg}^{-1}\right)$ was orally administered for 1 week and then the surface phenotype of cells was identified by using monoclonal antibodies. Stained cells were analyzed by flow cytometry on EPICS ELITE with logarithmic amplifier. Lymphoid cells were gated by the forward and side scatters gating method for the analysis of the lymphocytes population. Each value represents a mean \pm SD $(n=10)$. The differences between groups were analyzed by Welch's or Student's $t$-test. further studies on the $\mathrm{CD}^{-}$cells are needed. These results suggest that orally administered HET up-regulates the L-selectin positive cells in B lymphocytes.

\section{Discussion}

In order to analyze the effect of HET on IgA immune response against intestinal antigen, HET was administered to mice at a dose of $1000 \mathrm{mg} \mathrm{kg}^{-1}$ per day, which is equal to 20 -fold for the clinical dose applied in human, in this study. It is widely known that humans have a low metabolic ability on drugs (14). Inversely, drugs are metabolized in mice more quickly than humans. Indeed, the hepatic clearance of drugs in humans was approximately one-seventh of that of other mammalians including mice (15). Furthermore, when compared to renal clearance rate between humans and mice, clearance in mice is about 10 -fold greater than that of humans (16). Therefore, we used relatively high dosage.

OVA was chosen as an antigen because it has been used widely in immunological experiments and is a wellcharacterized antigen. However, oral administration of OVA alone is difficult to induce $\operatorname{IgA}$ immune response in gastric mucosa, because a small amount of the aqueous OVA antigen can be easily degraded in the digestive tract (17). Biodegradable microparticles have allowed protection of orally administered antigens against enzymatic degradation, to increase antigen uptake into the Peyer's patches through $\mathrm{M}$ cells, to enhance mucosal immune response and finally to induce a long and slow antigen release (18-20). Therefore, to induce the OVAspecific IgA antibody in mucosal site, OVA was entrapped into microparticles and then administered orally. By oral immunization of OVA-microparticle, OVA-specific IgA antibody was successfully induced in intestine and OVA-specific IgA titers in intestinal washes were significantly enhanced by oral administration of HET. These results suggest that orally administered HET 
may strengthen defensive systems against various pathogens and food antigens in intestine. So far as we know, this is the first description that oral administration of HET-enhanced mucosal IgA response against intestinal antigen.

The cytokine network plays an important role in inflammatory and immune responses (21-23). IFN- $\gamma$ and IL-4 are providing distinct help for either inflammatory or humoral immune responses, and are expressed in Th1 and Th2 cells, (24). Because the cytokine secretion pattern of lymphocytes shift towards a Th1-like response by oral administration of HET, the enhancement of mucosal IgA antibody response by HET can not be explained by the viewpoint of Th1-Th2 balance. Most of the IgA producing B cells and plasma cells are found in close proximity to the IEC, which lie on the surface of the intestine. These IEC transport the secreted IgA from the intestinal lamina propria across to the intestinal lumen and therefore play an important role in mucosal immune responses. However, several studies have shown that IEC have the capacity to produce several important immunoregulatory cytokines such as IL-6, IL-7, IL-8, IL-10, tumor necrosis factor- $\alpha$ and transforming growth factor- $\beta$ reviewed in references $(25,26)$. HET might modulate cytokine secretion of IEC, and the mucosal IgA antibody secretion might be enhanced through action of these cytokines.

Polymeric immunoglobulin receptor (pIgR), also called membrane secretory component (SC), of epithelial cells in mucosa functions as a receptor for $\operatorname{IgA}$ (27), and it facilitates the transport of $\operatorname{IgA}$ through epithelial cells into surface of mucosa. Thus, $\mathrm{pIgR}$ is thought to be a key factor in mucosal immunity. It has been reported that IFN- $\gamma$ enhances expression of $\operatorname{pIgR}(28,29)$. In this study, enhanced IFN- $\gamma$ secretion was observed by oral administration of HET (Fig. 4A-C). Therefore, it is inferred that HET up-regulates expression on $\mathrm{pIgR}$ of epithelial cells in mucosal site via stimulation of IFN- $\gamma$, and the enhanced pIgR might partly contribute to the enhanced IgA immune response. However, it is now not known whether HET up-regulate pIgR. Further studies are needed.

Mucosal immune systems in each local site such as gastrointestinal, pulmonary and genitourinary tracts and the exocrine glands connect each other through lymphocyte homing, and this intertissue communication is named as common mucosal immune system (CMIS) $(30,31)$. Orally administered HET enhanced $\operatorname{IgA}$ immune response in not only intestinal mucosa but also nasal mucosa against orally administered OVA-microparticles. The IgA immune response in nasal mucosa against intestinal antigen may be explained by lymphocytes homing via CMIS. However, detailed mechanism is not known how HET enhanced $\operatorname{IgA}$ immune response in nasal tissues distant from intestine. All high endothelial venules of the nasal-associated lymphoid tissue, as well as the draining head and neck lymph nodes referred to as cranial-, oral-, and nasal-associated lymphoid tissue, express peripheral lymph node vascular addressin (PNAd), and most lymphocytes binding to these tissues are mediated primarily through L-selectin-PNAd interactions $(32,33)$. Lymphocyte homing to the nasal cavity and bronchopulmonary tissues in the humans and sheep is mediated by L-selectin-PNAd interactions rather than by mucosal addressin cell adhesin molecule-1 (MAdCAM-1)- $\alpha 4 \beta 7$ integrin interactions (34-36). The results of DNA microarray and FCM analyses suggest that orally administered HET up-regulates L-selectin positive cells in B lymphocytes. Because L-selectin plays an important role in the recruitment of B lymphocyte to the non-intestinal mucosal effecter site $(37,38)$, the up-regulation of L-selectin positive B lymphocytes by HET might partly contribute to the enhancement of IgA immune response in nasal mucosa after oral immunization with OVA-microparticles. In addition to L-selectin gene, HET modulated the expression of seven genes (Table 1). Presumably these gene products also play important roles in the enhanced IgA immune response by HET. In order to clarify the mechanism of enhanced IgA immune response and role of these gene products, further studies are required.

Our results revealed that HET enhances the mucosal IgA immune response. HET consists of ten component crude drugs, and is known to contain various compounds, which may possess immunomodulatory and immunosuppressive effects. Therefore, these may complicate the interpretation of results. At this point, several possibilities can be considered. Perhaps the HET extract acts as a polyclonal B cell stimulator. Previously, we reported on potent mitogenic polysaccharides from Bupleuri Radix, Glycyrrhizae Radix, Astragali Radix, Atractylodis lanceae Rhizoma, Ginseng Radix and Angelicae Radix (39-41), which are component crude drugs of HET. These polysaccharides may play a role in the enhancement of IgA response via a polyclonal B cell activation as active constituents in HET. The mechanism of enhancement of IgA response by HET still remains obscure. To elucidate the action mechanisms of HET and active constituents in HET, further investigations are necessary.

\section{Acknowledgments}

We would like to thank Dr T. Takahashi (Kitasato University) and Prof. Dr H. Terada (Tokyo University of Science) for helpful discussion. A part of this work was supported by a Grants-in Aid for Scientific Research from Japan Society for the Promotion of Science. We would like to thank Dr I. Sakakibara (Tsumura \& Co.) for analyses of TJ-41 by 3D-HPLC, and Ms M. Inoue for her technical assistance. 


\section{References}

1. Cho JM, Sato N, Kikuchi K. Prophylactic antitumor effect of Hochu-ekki-to (TJ-41) by enhancing natural killer cell activity. In vivo 1991;5:389-92.

2. Kataoka T, Akagawa KS, Tokunaga T, Nagao S. Activation of macrophages with Hochu-ekki-to. Jpn J Cancer Chemother 1989;16:1490-3.

3. Mori K, Kido T, Daikuhara H, Sakakibara I, Sakata T, Shimizu K, et al. Effect of Hochu-ekki-to (TJ-41), a Japanese herbal medicine, on the survival of mice infected with influenza virus. Antivir Res 1999:44:103-11.

4. Kiyohara H, Nagai $T$, Munakata $K$, Nonaka $K$, Hanawa $T$, Kim SJ, et al. Stimulating effect of Japanese herbal (kampo) medicine, Hochuekkito on upper respiratory mucosal immune system. Evid Based Complement Alternat Med 2006;3:459-67.

5. McNabb PC. Host defense mechanisms at mucosal surfeces. Ann Rev Microbiol 1981;35:477-96.

6. Ruedl C, Wolf H. Features of oral immunization. Int Arch Allergy Immunol 1995;108:334-9.

7. Jeffery H, Davis SS, O'Hagan DT. The preparation and characterization of poly(lactide-co-glycolide) microparticles. II. The entrapment of a model protein using a (water-in-oil)-in-water emulsion solvent evaporation technique. Pharm Res 1993;10:362-8.

8. Smith PK, Krohn RI, Hermanson GT, Mallia AK, Gartner FH, Provenzano MD, et al. Measurement of protein using bicinchoninic acid. Anal Biochem 1985;150:76-85.

9. Matsumoto T, Yamada H. Orally administered kampo (Japanese herbal) medicine, "Juzen-Taiho-To" modulates cytokine secretion in gut associated lymphoreticular tissues in mice. Phytomedicine 2000;6:425-30.

10. Husband AJ, Gowans JL. The origin and antigen-dependent distribution of IgA-containing cells in the intestine. J Exp Med 1978:148:1146-60.

11. Gallatin WM, Weissman IL, Butcher EC. A cell-surface molecule involved in organ-specific homing of lymphocytes. Nature 1983;304:30-4.

12. Streeter PR, Rouse BT, Butcher EC. Immunohistologic and functional characterization of a vascular addressin involved in lymphocyte homing into peripheral lymph nodes. J Cell Biol 1988;107:1853-62.

13. Berg EL, Robinson MK, Warnock RA, Butcher EC. The human peripheral lymph node vascular addressin is a ligand for LECAM-1, the peripheral lymph node homing receptor. $J$ Cell Biol 1991:114:343-9.

14. Brodie BB. Of mice, microsomes and man. Pharmacologist 1964;6:12-26.

15. Boxenbaum $\mathrm{H}$. Interspecies variation in liver weight, hepatic blood flow, and antipyrine intrinsic clearance: extrapolation of data to benzodiazepines and phenytoin. $J$ Pharmacokinet Biopharm 1980;2:165-76.

16. Dedrick RL, Bischoff KB, Zaharko DS. Interspecies correlation of plasma concentration history of methotrexate (NSC-740). Cancer Chemother Rep 1970;54:95-101.

17. Nemoto-Kawamura C, Ishii $K$, Miyajima $H$, Hirahashi $T H$, Katoh T, Hayashi O. Effects of Spirulina phycocyanin ingestion on the mucosal antibody responses in mice. J Phys Fit Nutr Immunol 2003:13:102-11.

18. Challacombe SJ, Rahman D, Jeffery H, Davis SS, O'Hagan DT. Enhanced secretory $\operatorname{IgA}$ and systemic IgG antibody responses after oral immunization with biodegradable microparticles containing antigen. Immunology 1992;76:164-8.

19. Ermak TH, Dougherty EP, Bhagat HR, Kabok Z, Pappo J. Uptake and transport of copolymer biodegradable microspheres by rabbit Peyer's patch M cells. Cell Tissue Res 1995;279:433-6.

20. O'Hagan DT. The intestinal uptake of particles and the implications for drug and antigen delivery. J Anat 1996;189:477-82.

21. Balkwill FR, Burke F. The cytokine network. Immunol Today 1989;10:299-304.
22. Bellanti JA, Kadlec JV, Escobar-Gutierrez A. Cytokines and the immune response. Pediatr Clin North Am 1994;41:597-621.

23. Liles WC, Van Voorhis WC. Review: nomenclature and biologic significance of cytokines involved in inflammation and the host immune response. J Infect Dis 1995;172:1573-80.

24. Mosmann TR, Cherwinski H, Bond MW, Giedlin MA, Coffman RL. Two types of murine helper $\mathrm{T}$ cell clone. I. Definition according to profiles of lymphokine activities and secreted proteins. J Immunol 1986;136:2348-57.

25. Goodrich ME, McGee DW. Regulation of mucosal B cell immunoglobulin secretion by intestinal epithelial cell-derived cytokines. Cytokine 1998;10:948-55.

26. Kagnoff MF, Eckmann L. Epithelial cells as sensors for microbial infection. J Clin Invest 1997;100:6-10.

27. Brandtzaeg P, Prydz H. Direct evidence for an integrated function of $\mathbf{J}$ chain and secretory component in epithelial transport of immunoglobulins. Nature 1984;311:71-3.

28. Sollid LM, Kvale D, Brandtzaeg P, Markussen G, Thorsby E. Interferon- $\gamma$ enhances expression of secretory component, the epitherial receptor for polymeric immunoglobulins. J Immunol 1987;138:4303-6.

29. Phillips JO, Everson MO, Moldoveanu Z, Lue C, Mestecky J. Synergistic effect of IL-4 and IFN- $\gamma$ on the expression of polymeric Ig receptor (secretory component) and IgA binding by human epitherial cells. J Immunol 1990;145:1740-4.

30. McGhee JR, Mestecky J, Dertzbaugh MT. The mucosal immune system: from fundamental concepts to vaccine development. Vaccine 1992;10:75-88.

31. Kiyono H, Fukuyama S. NALT-versus Peyer's-patch-mediated mucosal immunity. Nat Rev Immunol 2004;4:699-710.

32. Csencsits KL, Jutila MA, Pascual DW. Nasal-associated lymphoid tissue: phenotypic and functional evidence for the primary role of peripheral node addressin in naive lymphocyte adhesion to high endothelial venules in a mucosal site. J Immunol 1999;163:1382-9.

33. Michie SA, Streeter PR, Bolt PA, Butcher EC, Picker LJ. The human peripheral lymph node vascular addressin: an inducible endothelial antigen involved in lymphocyte homing. Am J Pathol 1993;143:1688-98.

34. Abitorabi MA, Mackay CR, Jerome EH, Osorio O, Butcher EC, Erle DJ. Differential expression of homing molecules on recirculating lymphocytes from sheep gut, peripheral, and lung lymph. J Immunol 1996;156:3111-7.

35. Picker LJ, Martin RJ, Trumble A, Newman LS, Collins PA, Bergstresser PR, et al. Differential expression of lymphocyte homing receptors by human memory/effector $\mathrm{T}$ cells in pulmonary versus cutaneous immune effector sites. Eur J Immunol 1994;24:1269-77.

36. Quiding M, Lakew M, Granstrom G, Nordstrom I, Holmgren J, Czerkinsky C. Induction of specific antibody responses in the human nasopharyngeal mucosa. Adv Exp Med Biol 1995;371 B:1445-50.

37. Csencsits KL, Walters N, Pascual DW. Cutting edge: dichotomy of homing receptor dependence by mucosal effector B cells: E versus L-selectin. J Immunol 2001;167:2441-5.

38. Csencsits KL, Pascual DW. Absence of L-selectin delays mucosal B cell responses in nonintestinal effector tissues. $J$ Immunol 2002;169:5649-59.

39. Zhao JF, Kiyohara H, Yamada H, Takemoto N, Kawamura H. Heterogeneity and characterisation of mitogenic and anticomplementary pectic polysaccharides from the roots of Glycyrrhiza uralensis Fisch et D.C. Carbohydr Res 1991;219:149-72.

40. Yamada H, Kiyohara H, Takemoto N, Zhao JF, Kawamura H, Komatsu Y, et al. Mitogenic and complement activating activities of the herbal components of juzen-taiho-to. Planta Med 1992:58:166-70.

41. Sakurai MH, Matsumoto T, Kiyohara H, Yamada H. B-cell proliferation activity of pectic polysaccharide from a medicinal herb, the roots of Bupleurum falcatum L. and its structural requirement. Immunology 1999;97:540-7.

Received July 7, 2007; accepted September 18, 2007 


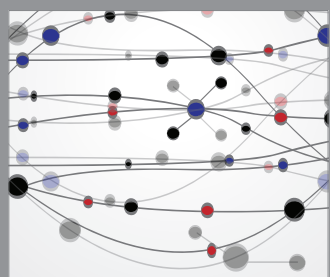

The Scientific World Journal
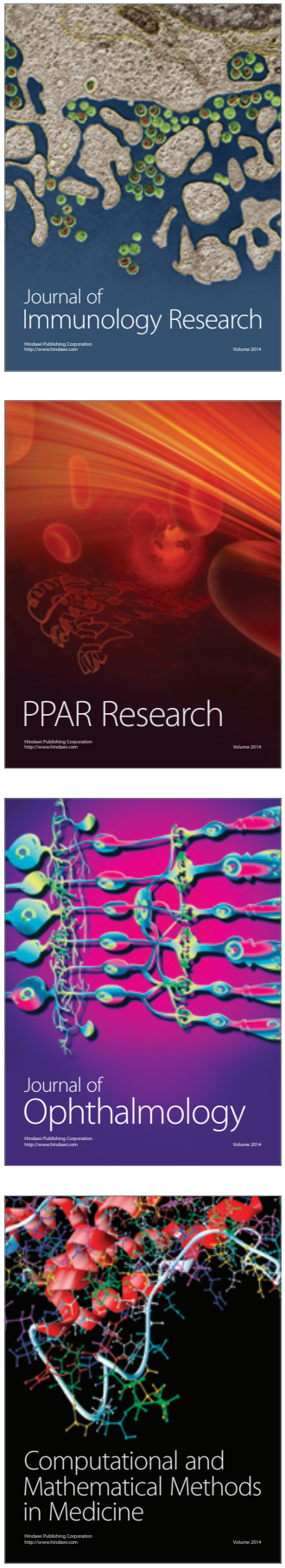

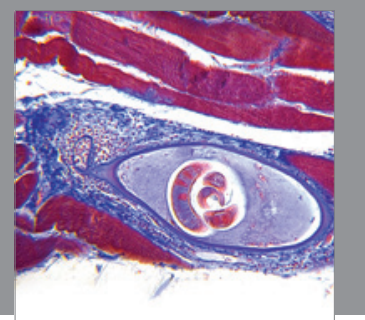

Gastroenterology

Research and Practice
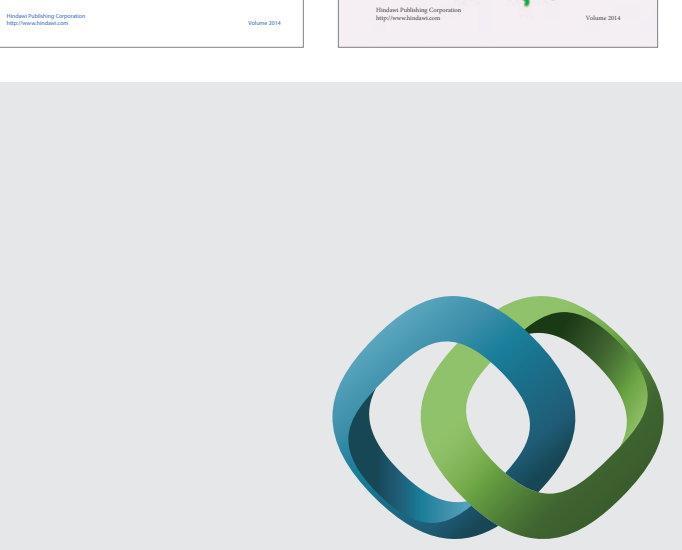

\section{Hindawi}

Submit your manuscripts at

http://www.hindawi.com
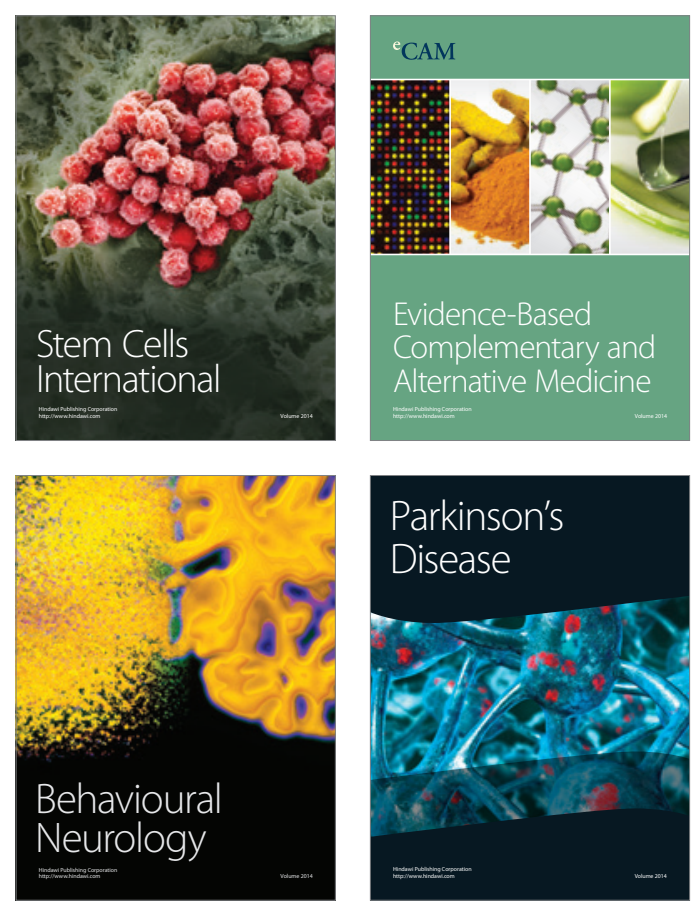

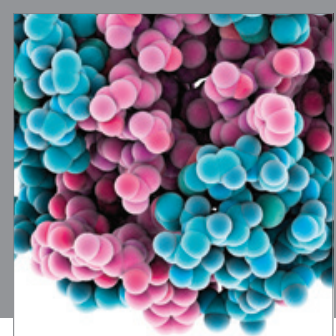

Journal of
Diabetes Research

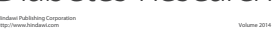

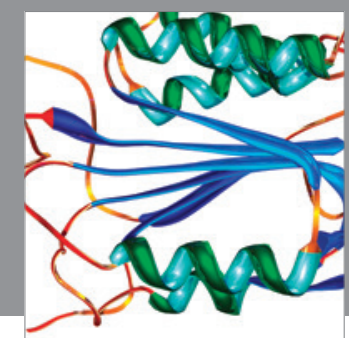

Disease Markers
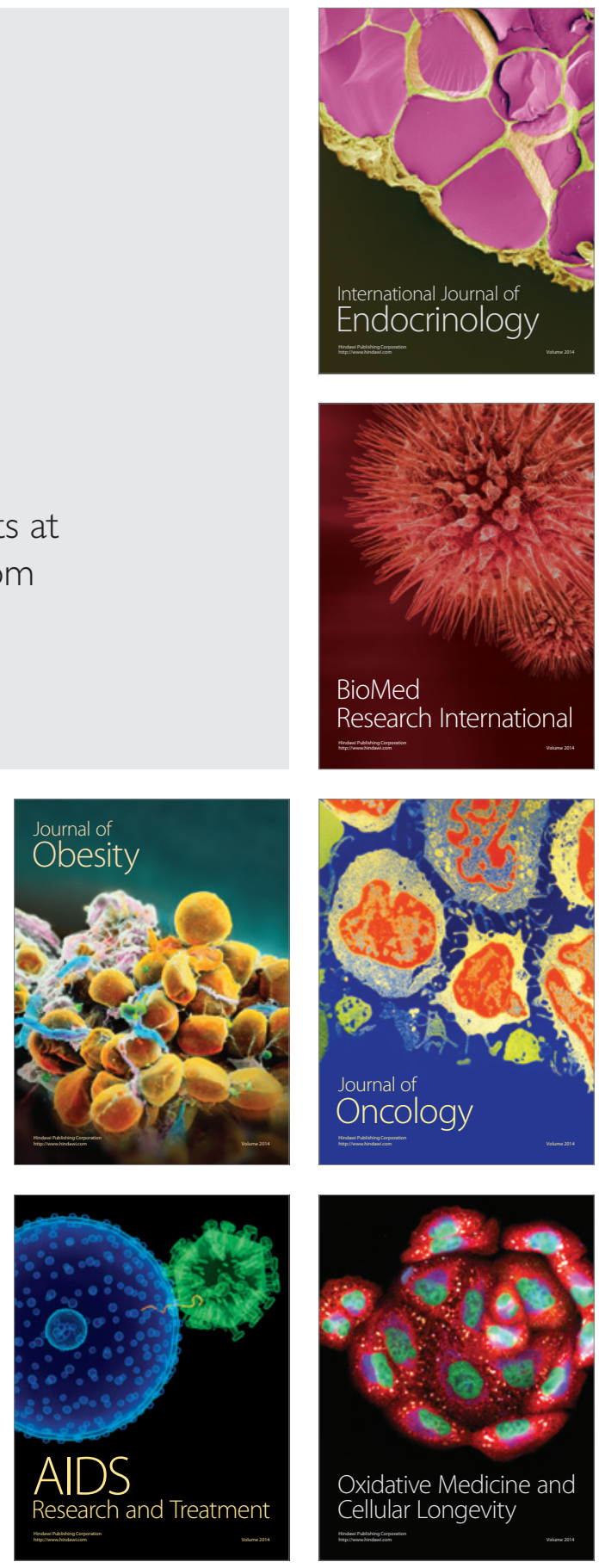